OPEN ACCESS

Edited by:

Juan J. Canales,

University of Tasmania,

Australia

Reviewed by:

Cristina Núñez,

University of Murcia, Spain

Katia Gysling,

Pontifical Catholic University of Chile,

Chile

${ }^{*}$ Correspondence:

Xian-Si Zeng

zxs-2005@vip.163.com

Jin-Jing Jia

jiajinjing1986@126.com

Specialty section:

This article was submitted to

Neuropharmacology,

a section of the journal

Frontiers in Pharmacology

Received: 22 October 2019

Accepted: 27 January 2020

Published: 21 February 2020

Citation:

Zeng X-S, Geng W-S, Wang Z-Q and Jia J-J (2020) Morphine Addiction and Oxidative Stress: The Potential

Effects of Thioredoxin-1.

Front. Pharmacol. 11:82.

doi: 10.3389/fphar.2020.00082

\section{Morphine Addiction and Oxidative Stress: The Potential Effects of Thioredoxin-1}

\author{
Xian-Si Zeng ${ }^{1 *}$, Wen-Shuo Geng ${ }^{1}$, Zhan-Qi Wang ${ }^{2}$ and Jin-Jing Jia ${ }^{1 *}$ \\ 1 Key Laboratory of Tea Plant Biology of Henan Province, College of Life Sciences, Xinyang Normal University, Xinyang, \\ China, ${ }^{2}$ Key Laboratory of Vector Biology and Pathogen Control of Zhejiang Province, College of Life Sciences, Huzhou \\ University, Huzhou, China
}

Long-term administration of morphine for the management of chronic pain will result in tolerance to its analgesic effect and could even cause drug dependence. Numerous studies have demonstrated significant redox alteration in morphine dependence and addiction. Thioredoxin-1 (Trx-1) play important roles in controlling the cellular redox balance. In recent years, several recent studies have demonstrated that Trx-1 may be a promising novel therapeutic target for morphine addiction. In this article, we firstly review the redox alteration in morphine addiction. We also summarize the expression and the protective roles of Trx-1 in morphine dependence. We further highlight the protection of geranylgeranylacetone (GGA), a noncytotoxic pharmacological inducer of Trx-1, in morphine-induced conditioned place preference. In conclusion, Trx-1 may be very promising for clinical therapy of morphine addiction in the future.

Keywords: morphine addiction, oxidative stress, CPP, thioredoxin-1, geranylgeranylacetone

\section{INTRODUCTION}

Morphine, the most effective opioid analgesic, is clinically used for severe acute and chronic pain. An increasing number of studies have clarified that morphine could display beneficial protection. Morphine at low concentrations promoted cell proliferation and suppressed nicotine-induced cytotoxicity and cell death in PC12 cells (Amini et al., 2019). Low-dose morphine played a neuroprotective role in cellular and animal models of Parkinson's disease through inhibiting oxidative stress and endoplasmic reticulum stress, promoting autophagy activation, and improving mitochondrial function (Wang et al., 2018). Acute administration with morphine alleviated 1methyl-4-phenyl-1, 2, 3, 6-tetrahydropyridine-induced tremor symptoms in monkeys (Yan et al., 2014). In addition, morphine protected PC12 cells against the cytotoxicity of 1-methyl-4phenylpyridinium through activating phosphatidylinositol 3-kinase (PI3K)/Akt pathway (Fan et al., 2019). Some groups demonstrated that preconditioning with morphine alleviated cerebral ischemia injury through activating the mTOR pathway (Arabian et al., 2018b) or mitochondrial KATP channels (Arabian et al., 2018a). However, repeated use of morphine will lead to various sideeffects, such as antinociceptive tolerance, dependence, and addiction. 


\section{MORPHINE ADDICTION}

Long-term treatment with morphine for the management of chronic pain will result in tolerance to the analgesic effect of morphine. In order to overcome tolerance, a higher dose of morphine is often required for the maintenance of analgesia, which will result in the development of severe sideeffects, including respiratory depression, withdrawal symptoms, and rewarding effects with a high risk of relapse (Eidson and Murphy, 2019). Morphine addiction has become a major public health issue. An increasing number of studies have revealed that several brain regions, such as the ventral tegmental area (VTA), nucleus accumbens (NAc), and hippocampus (Hipp), are involved in morphine addiction (Kim et al., 2016). Although mechanisms underlying morphine-mediated processes remain the subject of much debate, morphine stimulation activates $\mathrm{G}$ protein-coupled opioid receptors and then induces significant molecular changes inside the cell, such as an inhibition of adenylate cyclase activity, and activation of potassium channels (Qu et al., 2017; Yang et al., 2019). In addition, other signalling pathways, including mitogenactivated kinases (MAPK), $\beta$-arrestin, phospholipase $\mathrm{C}$, protein kinase, PI3K, and extracellular signal-regulated kinase (ERK) pathways, are also involved in morphine activity (Bianchi et al., 2010; Zhang and Pan, 2010; Dai et al., 2018; Shen et al., 2018; de Freitas et al., 2019; Dekan et al., 2019; Listos et al., 2019). Recently, the role of oxidative stress in morphine action has been paid more attention.

\section{Oxidative Stress in Morphine Addiction}

A growing body of evidence has indicated that oxidative stress is involved in the development of addiction with several addictive drugs, including cocaine, methamphetamine, and morphine (Kovacic, 2005; Cai et al., 2016; Jang et al., 2017). Morphine could activate opioid receptors, and its treatment not only promoted the generation of free radicals, including reactive oxygen (ROS) or reactive nitrogen (RNS) species, but also decreased the activities of antioxidants in target cells (Skrabalova et al., 2013). Morphine could induce ROS generation in a time- and concentration-dependent manner in SH-SY5Y cells and excessive ROS subsequently affected morphine addiction through involving $\mu$-opioid receptors (Ma et al., 2015). Systemic morphine use also led to oxidative stress in animals. Oxidative stress levels were increased in the prefrontal cortex and Hipp of morphine-dependent rats (Famitafreshi and Karimian, 2018). Abdel-Zaher and coworkers reported that glutamate levels and lipid peroxide malondialdehyde (MDA) levels were progressively increased in the brain of morphinetreated mice (Abdel-Zaher et al., 2013b). What's more, brain intracellular reduced glutathione (GSH) levels and glutathione peroxidase (GSH-Px) activity were decreased in mice (AbdelZaher et al., 2013a). In rats, subcutaneous injection of morphine also significantly increased lipid peroxidation, and decreased the activities of SOD and GSH-Px (Motaghinejad et al., 2015a). GSH levels were depleted in cerebrospinal fluid sampled from cancer patients administrated with morphine intracerebroventricularly, which might render the central nervous system vulnerable to damage from oxidative stress (Goudas et al., 1999). Morphine could alter intracellular levels of GSH-based cellular redox status, subsequently affect S-adenosylmethionine levels (Trivedi and Deth, 2014), and finally induce global DNA methylation changes (Trivedi et al., 2014).

In addition, morphine also affected other oxidative stressrelated proteins. Long-term treatment with morphine not only increased the MDA level, but also decreased activities of SOD, glutathione-s-transfrase (GST), and catalase (CAT) in the liver of rats (Samarghandian et al., 2014). Morphine accelerated the disease progression of HIV-infection in macaques due to the deteriorated oxidative stress, including the 50\% drop of CAT and SOD (Perez-Casanova et al., 2007). In rat primary neuronal striatal cells, three oxidative stress-related proteins glyceraldehyde-3-phosphate dehydrogenase (GAPDH), dihydrolipoyl dehydrogenase (DLDH), and aldehyde dehydrogenase (ALDH) - were significantly upregulated after morphine administration (Bodzon-Kulakowska et al., 2009). Proteomic analysis demonstrated that oxidative stress-related proteins, such as peroxiredoxin- 2 and Heat shock protein 70 (Hsp70), were significantly decreased in the NAc of morphinedependent monkeys (Bu et al., 2012) (Table 1).

TABLE 1 | Morphine-induced oxidative stress in cells, rodents, non-human primates and human.

\begin{tabular}{|c|c|c|c|}
\hline Species & Morphine treatment & Effects & References \\
\hline $\begin{array}{l}\text { human SH- } \\
\text { SY5Y cells }\end{array}$ & $50 \mu \mathrm{M}$ for 24 hour & $\begin{array}{l}\uparrow R O S \\
\text { generation }\end{array}$ & (Ma et al., 2015) \\
\hline $\begin{array}{l}\text { Rat primary } \\
\text { neuronal } \\
\text { striatal cells }\end{array}$ & $10 \mu \mathrm{M}$ for 5 days & $\begin{array}{l}\text { } \mathrm{GAPDH}, \\
\mathrm{DLDH} \text { and } \\
\text { ALDH }\end{array}$ & $\begin{array}{l}\text { (Bodzon- } \\
\text { Kulakowska } \\
\text { et al., 2009) }\end{array}$ \\
\hline Rats & 5 mg/kg for 14 days (i.p.) & $\uparrow M D A, \downarrow G S H$ & $\begin{array}{l}\text { (Famitafreshi } \\
\text { and Karimian, } \\
\text { 2018) }\end{array}$ \\
\hline Rats & $\begin{array}{l}4 \mathrm{mg} / \mathrm{kg} \text { for } 1^{\text {st }} 10 \text { days, } 8 \mathrm{mg} / \\
\mathrm{kg} 2^{\text {nd }} 10 \text { days and } 12 \mathrm{mg} / \mathrm{kg} \\
\text { for } 3^{\text {rd }} 10 \text { days (i.p.) }\end{array}$ & $\begin{array}{l}\text { †liver MDA and } \\
\text { nitric oxide, } \\
\downarrow \text { liver SOD, } \\
\text { GST and CAT }\end{array}$ & $\begin{array}{l}\text { (Samarghandian } \\
\text { et al., 2014) }\end{array}$ \\
\hline Rats & 45 mg/kg for 4 weeks (s.c.) & $\begin{array}{l}\text { ^lipid } \\
\text { peroxidation, } \\
\downarrow \text { SOD and } \\
\text { GSH-Px }\end{array}$ & $\begin{array}{l}\text { (Motaghinejad } \\
\text { et al., 2015a) }\end{array}$ \\
\hline Mice & $\begin{array}{l}5 \mathrm{mg} / \mathrm{kg} \text { twice daily for } 7 \text { days } \\
\text { (s.c.) }\end{array}$ & $\begin{array}{l}\uparrow M D A \text { and } \\
\text { nitric oxide, } \\
\downarrow \text { GSH and } \\
\text { GSH-PX }\end{array}$ & $\begin{array}{l}\text { (Abdel-Zaher } \\
\text { et al., 2013a; } \\
\text { Abdel-Zaher } \\
\text { et al., 2013b) }\end{array}$ \\
\hline $\begin{array}{l}\text { Rhesus } \\
\text { monkeys }\end{array}$ & $\begin{array}{l}3 \mathrm{mg} / \mathrm{kg} \text { (day 1-7), } 6 \mathrm{mg} / \mathrm{kg} \\
\text { (day 8-14), } 9 \mathrm{mg} / \mathrm{kg} \text { (day 15- } \\
21), 12 \mathrm{mg} / \mathrm{kg} \text { (day 22-28), } 15 \\
\mathrm{mg} / \mathrm{kg} \text { (day 29-90) (s.c.) }\end{array}$ & $\begin{array}{l}\downarrow \text { peroxiredoxin- } \\
2 \text { and Hsp70 }\end{array}$ & (Bu et al., 2012) \\
\hline Macaques & $\begin{array}{l}5 \text { mg/kg (TID) for } 20 \text { weeks } \\
\text { (i.m.) }\end{array}$ & $\begin{array}{l}\uparrow M D A, \downarrow C A T \\
\text { and SOD }\end{array}$ & $\begin{array}{l}\text { (Perez- } \\
\text { Casanova et al., } \\
\text { 2007) }\end{array}$ \\
\hline $\begin{array}{l}\text { Cancer } \\
\text { patients }\end{array}$ & $0.3 \mathrm{mg}$ (icv.) & $\begin{array}{l}\downarrow \text { cerebrospinal } \\
\text { fluid GSH }\end{array}$ & $\begin{array}{l}\text { (Goudas et al., } \\
\text { 1999) }\end{array}$ \\
\hline
\end{tabular}

i.p., intraperitoneally; s.c., subcutaneously; i.m., intramuscularly; icv., intracerebroventricularly. 


\section{Maintaining Redox Balance Inhibits Morphine Action}

Given the redox alteration in morphine action, antioxidants may provide a protective role in morphine addiction. SOD is an important intracellular antioxidant. Repeated doses of morphine in mice significantly decreased the activity of the mitochondrial isoform of MnSOD in the dorsal horn of the spinal cord due to the nitration of MnSOD by morphine (Muscoli et al., 2007). SOD-mimetic-agent-injection attenuated the effects of morphine on mitochondrial SOD activity (Motaghinejad et al., 2015b). MnSOD overexpressed by recombinant herpes simplex virus in the periaqueductal gray of morphine-withdrawn rats suppressed the upregulated mitochondrial superoxide and the activation of endoplasmic reticulum stress (Iida et al., 2017).

Numerous studies have demonstrated that exogenous agents providing antioxidant activity could also inhibit the action of morphine. The accepted antioxidant, $\mathrm{N}$-acetyl-cysteine, reversed the down-regulation of antioxidant genes (CAT and CuSOD) in SH-SY5Y cells treated with morphine (Saify et al., 2016). The antidepressant Venlafaxine prevented morphine antinociceptive tolerance at least partly because of its antioxidative properties, including the down-regulation of MDA and inhibition of total thiol and GSH-Px levels in the brains of mice (Mansouri et al., 2018). Fluoxetine, another prescribed antidepressant, also seemed a promising adjuvant to opioid analgesics due to its inhibition of morphine-induced changes in prooxidantantioxidant balance (Hamdy et al., 2018). Atorvastatin, a lipidlowering medication, could exhibit protective effects against both tolerance to antinociceptive effects of morphine and withdrawalinduced behaviors via normalizing the increased MDA in withdrawn mice (Pajohanfar et al., 2017). The polyphenol curcumin, the most abundant component of traditional Chinese medicine Curcuma longa, has antioxidant, antiapoptotic, anti-inflammatory, immunomodulatory, anticancer, and neuroprotective properties. Curcumin lowered the increased lipid peroxidation and mitochondrial GSSG (oxidized GSH) levels in morphine-treated rats (Motaghinejad et al., 2015a) and attenuated morphine tolerance and dependence by inhibiting the activity of $\mathrm{Ca}^{2+} /$ calmodulin-dependent protein kinase II $\alpha$ (Hu et al., 2015). These studies suggest that the blocking effects of antioxidants to the action of morphine may provide a promising therapeutic strategy.

\section{THIOREDOXIN}

The thioredoxin (Trx) system, comprising Trx, thioredoxin reductase (TrxR), and coenzyme NADPH, plays a critical role in maintaining the cellular environment in a reduced state in both prokaryotes and eukaryotes (Holmgren and Lu, 2010). Human $\operatorname{Trx}$ is a $12 \mathrm{kDa}$ multifunctional protein with a conserved redox catalytic site (-Cys-Gly-Pro-Cys-) (Bai et al., 2003). The mutual transformation of dithiol and disulfide means Trx plays a vital role in regulating cellular redox balance (Jia et al., 2019). Trx-1, a major isoform located to cytoplasm, can directly scavenge ROS induced by a wide variety of stressors, such as UV irradiation and viral infections. Trx-1 can also inhibit cellular apoptosis (Zeng et al., 2015) because it acts as an endogenous negative regulator of apoptosis signal-regulating kinase 1 (ASK1) in the cytoplasm and inhibits ASK1dependent apoptotic pathway (Saitoh et al., 1998). It has been reported that Trx-1 expression is enhanced in both chronic and acute stress models and attenuate epinephrine stress-induced DNA damage via the negative regulation of $\beta$-arrestin-1 (Jia et al., 2014; Jia et al., 2016). Our previous studies have demonstrated that Trx-1 shows a neuroprotective role in central nervous system diseases, including Parkinson's disease and cerebral ischemia (Zeng et al., 2014; Zeng et al., 2018). Interestingly, Trx-1 is involved in the addiction of drugs, including morphine (Luo et al., 2013; Guo et al., 2018).

\section{The Increased Expression and the Role of Trx-1 Upon Morphine Administration}

So far, only a few studies have reported that Trx-1 expression is increased upon morphine administration. Trx-1 was induced through opioid receptors and the activation of PI3K and ERK pathways in morphine-treated SH-SY5Y cells (Luo et al., 2012a). Morphine exposure increased the expression of Trx-1 in dentate gyrus (DG, a brain region involved in memory consolidation), which was reversed by the pretreatment of a corticotropin-releasing factor 1 receptor (CRF1R) antagonist, CP-154,526, with no changes in the paraventricular nucleus (PVN) (Garcia-Carmona et al., 2015). García-Carmona and coworkers found that phosphorylated cAMPresponsive element-binding protein ( $\mathrm{p}$-CREB) positive neurons in DG also expressed Trx-1 (Garcia-Carmona et al., 2015), suggesting that Trx-1 could activate CREB and increase the rewarding effects of morphine (Table 2). The results are consistent with another study in which Trx-1 ameliorated the learning and memory deficits in a mouse model of Parkinson's disease via the restoration of p-CREB in the Hipp (Zhang et al., 2018).

Morphine also markedly increased the expression of Trx-1 in the nucleus accumbens (NAc) of C57BL/6 mice (Luo et al., 2012b). Interestingly, the Trx-1 expression showed a notable elevation in the liver and kidney of morphine-treated mice (Luo et al., 2013).

TABLE 2 | The effects and molecular mechanisms of Trx-1 and GGA on morphine addiction.

\begin{tabular}{|c|c|c|c|}
\hline Brain areas & Effects & Mechanisms & References \\
\hline DG & $\begin{array}{l}\text { Morphine-induced } \\
\text { increase of Trx-1 } \\
\text { enhanced the } \\
\text { rewarding effects }\end{array}$ & Activating CREB & $\begin{array}{l}\text { (Garcia- } \\
\text { Carmona } \\
\text { et al., 2015) }\end{array}$ \\
\hline VTA and NAc & $\begin{array}{l}\text { Overexpression of } \\
\text { Trx-1 inhibited } \\
\text { morphine-induced } \\
\text { CPP }\end{array}$ & $\begin{array}{l}\text { Upregulating the } \\
\text { endogenous concentration } \\
\text { of GABA and the } \\
\text { expression of } G A B A_{B} \\
\text { receptor }\end{array}$ & $\begin{array}{l}\text { (Li et al., } \\
\text { 2018) }\end{array}$ \\
\hline NAc & $\begin{array}{l}\text { Inhibiting CPP and } \\
\text { attenuating the } \\
\text { naloxone-induced } \\
\text { withdrawal syndrome }\end{array}$ & $\begin{array}{l}\text { Suppressing the activation } \\
\text { of CREB, and the } \\
\text { expression of } \triangle F \text { FosB and } \\
\text { cyclin-dependent kinase } 5\end{array}$ & $\begin{array}{l}\text { (Luo et al., } \\
\text { 2012b) }\end{array}$ \\
\hline $\begin{array}{l}\text { NAc and } \\
\text { hippocampus }\end{array}$ & $\begin{array}{l}\text { Inhibiting morphine } \\
\text { reinstatement- } \\
\text { induced CPP }\end{array}$ & $\begin{array}{l}\text { Attenuating the activation of } \\
\text { NR2B/p-CaMKII/p-ERK/p- } \\
\text { CREB pathway }\end{array}$ & $\begin{array}{l}\text { (Guo et al., } \\
\text { 2018) }\end{array}$ \\
\hline
\end{tabular}


Trx-1 expression was induced by morphine in the ventral tegmental area (VTA) and NAc of mice (Li et al., 2018), two brain regions involved in morphine-induced conditioned place preference (CPP) for both opiates and psychostimulants (Edwards et al., 2017; Zhang et al., 2019). Li et al. further clarified that Trx-1 overexpression in transgenic mice inhibited morphine-induced CPP through upregulating the endogenous concentration of $\gamma$-aminobutyric acid (GABA) and the expression of $\mathrm{GABA}_{\mathrm{B}}$ receptor in the VTA and NAc (Li et al., 2018) (Table 2). Considering the critical role of Trx-1 in maintaining the cellular redox state, the increase of Trx-1 expression in morphine-induced CPP might be a compensatory mechanism of stress systems for the maintenance of neuroprotection.

\section{The Effects of Geranylgeranylacetone on Morphine Treatment}

Geranylgeranylacetone (GGA) is a clinical drug, extensively used for ulcer therapy (Ooie et al., 2001). Now GGA has become an accepted pharmacological inducer of Trx-1 (Tanito et al., 2005). Luo et al. demonstrated that pre-treatment with GGA significantly reduced morphine-induced locomotion, inhibited the CPP, and attenuated the naloxone-induced withdrawal syndromes, such as jumping, forepaw tremor, and rearing, through suppressing the activation of CREB, and inhibiting the expressions of $\triangle$ FosB and cyclin-dependent kinase 5 in the NAc of C57BL/6 mice (Luo et al., 2012b). Interestingly, the effect of increased Trx-1 by GGA on the activation of CREB in the NAc is contrary to that by CP-154,526 in DG (Garcia-Carmona et al., 2015). In addition, GGA also inhibited reinstatement of morphine-induced CPP through strengthening the expression of Trx-1 and regulating the N-methyl d-aspartate receptor $2 \mathrm{~B}$ subunit (NR2B)/ERK pathway in the NAc and Hipp, a brain region participating in associative processes such as declarative memory (Guo et al., 2018) (Table 2), suggesting that GGA may be a promising therapeutic drug for morphine-induced relapse. These studies suggest that enhancement of Trx-1 expression in the brain by using noncytotoxic pharmacological inducers may provide a novel therapeutic strategy for morphine dependence.

\section{CONCLUSION AND EXPECTATION}

In summary, chronic morphine treatment has been shown to lead to oxidative stress, which plays an important role in the development of morphine tolerance and dependence. An increasing number of studies have clarified that maintaining redox balance through restoration of endogenous antioxidant proteins or treatment with antioxidant agents inhibits the action

\section{REFERENCES}

Abdel-Zaher, A. O., Mostafa, M. G., Farghaly, H. S., Hamdy, M. M., and AbdelHady, R. H. (2013a). Role of oxidative stress and inducible nitric oxide synthase in morphine-induced tolerance and dependence in mice. Effect of alpha-lipoic acid. Behav. Brain Res. 247, 17-26. doi: 10.1016/j.bbr.2013.02.034

Abdel-Zaher, A. O., Mostafa, M. G., Farghly, H. M., Hamdy, M. M., Omran, G. A., and Al-Shaibani, N. K. (2013b). Inhibition of brain oxidative of morphine. As an antioxidant protein, Trx-1 could effectively inhibit the effects of morphine administration. In this article we reviewed that overexpression of Trx-1 or enhancement of Trx-1 expression by GGA, the noncytotoxic pharmacological inducer of Trx-1, inhibited morphine-induced CPP. At this stage, the studies are extremely few and limited to focusing on the effects of Trx-1 on morphine addiction mainly in rodent models. Their effects on morphine withdrawal and relapse should be investigated in future research. Besides that, nonhuman primate models of morphine addiction should be also developed to accelerate the clinical application of Trx-1 in the future. Trx-1 will provide a novel therapeutic strategy for morphine abuse.

Remarkably, GGA is also the pharmacological inducer of Hsp70, a soluble intracellular chaperone protein (Lennikov et al., 2013). Although GGA was reported to protect mice against morphine-induced hyperlocomotion, rewarding effect, and withdrawal syndromes, as well as morphine-induced hepatic and renal damage (Luo et al., 2012b; Luo et al., 2013), GGAinduced Hsp70 expression in the core of NAc promoted the development of behavioral sensitization, an important behavioral characteristic of drug-addicted animals, providing a biological target for long-lasting adaptations with relevance to morphine addiction (Wang et al., 2014).Recent research has reported that pre-treatment with an Hsp70 transcriptional inducer GGA promoted the development of morphine analgesic tolerance (Qin et al., 2019), suggesting that GGA is not clinically beneficial to the analgesic effect of morphine. Regarding these effects of GGA, further studies are needed to develop much more optimal pharmacological inducers of Trx-1.

\section{AUTHOR CONTRIBUTIONS}

$\mathrm{X}-\mathrm{SZ}$ and J-JJ conceptualized the idea for the article. X-SZ and W-SG wrote the final manuscript. X-SZ, Z-QW, and J-JJ revised the manuscript.

\section{ACKNOWLEDGMENTS}

This study was supported by the National Natural Science Foundation of China (31600837), Henan Science and Technology Project (172102310622), the Henan Science and Technology Innovation Team (Investigation on Plant Resources in Dabie Mountains), the Study and Utilization of Active Components of Special Plants (2017083), the Ph.D. Early Development Program (0201427, 16083), and Nanhu Scholars Program for Young Scholars of XYNU.

stress and inducible nitric oxide synthase expression by thymoquinone attenuates the development of morphine tolerance and dependence in mice. Eur. J. Pharmacol. 702 (1-3), 62-70. doi: 10.1016/j.ejphar. 2013.01.036

Amini, K., Zhaleh, H., Tahvilian, R., and Farnia, V. (2019). Low concentration of morphine protects against cell death, oxidative stress and calcium accumulation by nicotine in PC12 cells. Bratisl Lek. Listy 120 (4), 256-262. doi: 10.4149/BLL_2019_042 
Arabian, M., Aboutaleb, N., Soleimani, M., Ajami, M., Habibey, R., and PazokiToroudi, H. (2018a). Activation of mitochondrial KATP channels mediates neuroprotection induced by chronic morphine preconditioning in hippocampal CA-1 neurons following cerebral ischemia. Adv. Med. Sci. 63 (2), 213-219. doi: 10.1016/j.advms.2017.11.003

Arabian, M., Aboutaleb, N., Soleimani, M., Ajami, M., Habibey, R., Rezaei, Y., et al. (2018b). Preconditioning with morphine protects hippocampal CA1 neurons from ischemia-reperfusion injury via activation of the mTOR pathway. Can. J. Physiol. Pharmacol. 96 (1), 80-87. doi: 10.1139/cjpp-2017-0245

Bai, J., Nakamura, H., Kwon, Y. W., Hattori, I., Yamaguchi, Y., Kim, Y. C., et al. (2003). Critical roles of thioredoxin in nerve growth factor-mediated signal transduction and neurite outgrowth in PC12 cells. J. Neurosci. 23 (2), 503-509. doi: 10.1523/JNEUROSCI.23-02-00503.2003

Bianchi, E., Lehmann, D., Vivoli, E., Norcini, M., and Ghelardini, C. (2010). Involvement of PLC-beta3 in the effect of morphine on memory retrieval in passive avoidance task. J. Psychopharmacol. 24 (6), 891-896. doi: 10.1177/ 0269881108102013

Bodzon-Kulakowska, A., Suder, P., Mak, P., Bierczynska-Krzysik, A., Lubec, G., Walczak, B., et al. (2009). Proteomic analysis of striatal neuronal cell cultures after morphine administration. J. Sep. Sci. 32 (8), 1200-1210. doi: 10.1002/ jssc.200800464

Bu, Q., Yang, Y., Yan, G., Hu, Z., Hu, C., Duan, J., et al. (2012). Proteomic analysis of the nucleus accumbens in rhesus monkeys of morphine dependence and withdrawal intervention. J. Proteomics 75 (4), 1330-1342. doi: 10.1016/ j.jprot.2011.11.008

Cai, Y., Yang, L., Hu, G., Chen, X., Niu, F., Yuan, L., et al. (2016). Regulation of morphine-induced synaptic alterations: role of oxidative stress, ER stress, and autophagy. J. Cell Biol. 215 (2), 245-258. doi: 10.1083/jcb.201605065

Dai, W. L., Liu, X. T., Bao, Y. N., Yan, B., Jiang, N., Yu, B. Y., et al. (2018). Selective blockade of spinal D2DR by levo-corydalmine attenuates morphine tolerance via suppressing PI3K/Akt-MAPK signaling in a MOR-dependent manner. Exp. Mol. Med. 50 (11), 148. doi: 10.1038/s12276-018-0175-1

de Freitas, B. G., Pereira, L. M., Santa-Cecilia, F. V., Hosch, N. G., Picolo, G., Cury, Y., et al. (2019). Mitogen-activated protein kinase signaling mediates morphine induced-delayed hyperalgesia. Front. Neurosci. 13, 1018. doi: 10.3389/ fnins.2019.01018

Dekan, Z., Sianati, S., Yousuf, A., Sutcliffe, K. J., Gillis, A., Mallet, C., et al. (2019). A tetrapeptide class of biased analgesics from an Australian fungus targets the micro-opioid receptor. Proc. Natl. Acad. Sci. U. S. A. 116 (44), 22353-22358. doi: 10.1073/pnas.1908662116

Edwards, N. J., Tejeda, H. A., Pignatelli, M., Zhang, S., McDevitt, R. A., Wu, J., et al. (2017). Circuit specificity in the inhibitory architecture of the VTA regulates cocaine-induced behavior. Nat. Neurosci. 20 (3), 438-448. doi: $10.1038 / \mathrm{nn} .4482$

Eidson, L. N., and Murphy, A. Z. (2019). Inflammatory mediators of opioid tolerance: Implications for dependency and addiction. Peptides 115, 51-58. doi: 10.1016/j.peptides.2019.01.003

Famitafreshi, H., and Karimian, M. (2018). Socialization alleviates burden of oxidative-stress in hippocampus and prefrontal cortex in morphine addiction period in male rats. Curr. Mol. Pharmacol. 11 (3), 254-259. doi: 10.2174/ 1874467210666170919161045

Fan, Y., Chen, Y., Zhang, S., Huang, M., Wang, S., Li, Y., et al. (2019). Morphine reverses the effects of 1-methyl-4-phenylpyridinium in PC12 cells through activating PI3K/Akt. Int. J. Neurosci. 129 (1), 30-35. doi: 10.1080/ 00207454.2018.1492575

Garcia-Carmona, J. A., Camejo, D. M., Almela, P., Jimenez, A., Milanes, M. V., Sevilla, F., et al. (2015). CP-154,526 modifies CREB phosphorylation and thioredoxin-1 expression in the dentate gyrus following morphine-induced conditioned place preference. PloS One 10 (8), e0136164. doi: 10.1371/ journal.pone. 0136164

Goudas, L. C., Langlade, A., Serrie, A., Matson, W., Milbury, P., Thurel, C., et al. (1999). Acute decreases in cerebrospinal fluid glutathione levels after intracerebroventricular morphine for cancer pain. Anesth. Analg. 89 (5), 1209-1215. doi: 10.1213/00000539-199911000-00023

Guo, N., Zhang, X., Huang, M., Li, X., Li, Y., Zhou, X., et al. (2018). Geranylgeranylacetone blocks the reinstatement of morphine-conditioned place preference. Neuropharmacology 143, 63-70. doi: 10.1016/ j.neuropharm.2018.09.027
Hamdy, M. M., Elbadr, M. M., and Barakat, A. (2018). Fluoxetine uses in nociceptive pain management: a promising adjuvant to opioid analgesics. Fundam Clin. Pharmacol. 32 (5), 532-546. doi: 10.1111/fcp.12383

Holmgren, A., and Lu, J. (2010). Thioredoxin and thioredoxin reductase: current research with special reference to human disease. Biochem. Biophys. Res. Commun. 396 (1), 120-124. doi: 10.1016/j.bbrc.2010.03.083

Hu, X., Huang, F., Szymusiak, M., Liu, Y., and Wang, Z. J. (2015). Curcumin attenuates opioid tolerance and dependence by inhibiting $\mathrm{Ca} 2+/$ calmodulindependent protein kinase II alpha activity. J. Pharmacol. Exp. Ther. 352 (3), 420-428. doi: 10.1124/jpet.114.219303

Iida, T., Yi, H., Liu, S., Ikegami, D., Zheng, W., Liu, Q., et al. (2017). MnSOD mediated by HSV vectors in the periaqueductal gray suppresses morphine withdrawal in rats. Gene Ther. 24 (5), 314-324. doi: 10.1038/gt.2017.22

Jang, E. Y., Yang, C. H., Hedges, D. M., Kim, S. P., Lee, J. Y., Ekins, T. G., et al. (2017). The role of reactive oxygen species in methamphetamine selfadministration and dopamine release in the nucleus accumbens. Addict. Biol. 22 (5), 1304-1315. doi: 10.1111/adb.12419

Jia, J. J., Zeng, X. S., Zhou, X. S., Li, Y., and Bai, J. (2014). The induction of thioredoxin-1 by epinephrine withdraws stress via interaction with betaarrestin-1. Cell Cycle 13 (19), 3121-3131. doi: 10.4161/15384101.2014.949214

Jia, J. J., Zeng, X. S., Li, K., Ma, L. F., Chen, L., and Song, X. Q. (2016). The expression of thioredoxin-1 in acute epinephrine stressed mice. Cell Stress Chaperones 21 (5), 935-941. doi: 10.1007/s12192-016-0722-4

Jia, J. J., Geng, W. S., Wang, Z. Q., Chen, L., and Zeng, X. S. (2019). The role of thioredoxin system in cancer: strategy for cancer therapy. Cancer Chemother. Pharmacol. 84 (3), 453-470. doi: 10.1007/s00280-019-03869-4

Kim, J., Ham, S., Hong, H., Moon, C., and Im, H. I. (2016). Brain Reward Circuits in Morphine Addiction. Mol. Cells 39 (9), 645-653. doi: 10.14348/ molcells.2016.0137

Kovacic, P. (2005). Role of oxidative metabolites of cocaine in toxicity and addiction: oxidative stress and electron transfer. Med. Hypotheses 64 (2), 350-356. doi: 10.1016/j.mehy.2004.06.028

Lennikov, A., Kitaichi, N., Kase, S., Noda, K., Horie, Y., Nakai, A., et al. (2013). Induction of heat shock protein 70 ameliorates ultraviolet-induced photokeratitis in mice. Int. J. Mol. Sci. 14 (1), 2175-2189. doi: 10.3390/ ijms 14012175

Li, X., Huang, M., Yang, L., Guo, N., Yang, X., Zhang, Z., et al. (2018). Overexpression of thioredoxin-1 blocks morphine-induced conditioned place preference through regulating the interaction of gamma-aminobutyric acid and dopamine systems. Front. Neurol. 9, 309. doi: 10.3389/fneur.2018.00309

Listos, J., Lupina, M., Talarek, S., Mazur, A., Orzelska-Gorka, J., and Kotlinska, J. (2019). The Mechanisms involved in morphine addiction: an overview. Int. J. Mol. Sci. 20 (17), 4302. doi: 10.3390/ijms20174302

Luo, F. C., Feng, Y. M., Zhao, L., Li, K., Wang, S. D., Song, J. Y., et al. (2012a). Thioredoxin-1 expression regulated by morphine in SH-SY5Y cells. Neurosci. Lett. 523 (1), 50-55. doi: 10.1016/j.neulet.2012.06.039

Luo, F. C., Qi, L., Lv, T., Wang, S. D., Liu, H., Nakamura, H., et al. (2012b). Geranylgeranylacetone protects mice against morphine-induced hyperlocomotion, rewarding effect, and withdrawal syndrome. Free Radic. Biol. Med. 52 (7), 1218-1227. doi: 10.1016/j.freeradbiomed.2012.01.004

Luo, F. C., Zhao, L., Deng, J., Liang, M., Zeng, X. S., Liu, H., et al. (2013). Geranylgeranylacetone protects against morphine-induced hepatic and renal damage in mice. Mol. Med. Rep. 7 (2), 694-700. doi: 10.3892/mmr.2012.1217

Ma, J., Yuan, X., Qu, H., Zhang, J., Wang, D., Sun, X., et al. (2015). The role of reactive oxygen species in morphine addiction of SH-SY5Y cells. Life Sci. 124, 128-135. doi: 10.1016/j.lfs.2015.01.003

Mansouri, M. T., Naghizadeh, B., Ghorbanzadeh, B., Alboghobeish, S., Amirgholami, N., Houshmand, G., et al. (2018). Venlafaxine prevents morphine antinociceptive tolerance: The role of neuroinflammation and the 1-arginine-nitric oxide pathway. Exp. Neurol. 303, 134-141. doi: 10.1016/ j.expneurol.2018.02.009

Motaghinejad, M., Karimian, M., Motaghinejad, O., Shabab, B., Yazdani, I., and Fatima, S. (2015a). Protective effects of various dosage of Curcumin against morphine induced apoptosis and oxidative stress in rat isolated hippocampus. Pharmacol. Rep. 67 (2), 230-235. doi: 10.1016/j.pharep.2014.09.006

Motaghinejad, M., Karimian, S. M., Motaghinejad, O., Shabab, B., Asadighaleni, M., and Fatima, S. (2015b). The effect of various morphine weaning regimens on the sequelae of opioid tolerance involving physical dependency, anxiety and 
hippocampus cell neurodegeneration in rats. Fundam Clin. Pharmacol. 29 (3), 299-309. doi: 10.1111/fcp.12121

Muscoli, C., Cuzzocrea, S., Ndengele, M. M., Mollace, V., Porreca, F., Fabrizi, F., et al. (2007). Therapeutic manipulation of peroxynitrite attenuates the development of opiate-induced antinociceptive tolerance in mice. J. Clin. Invest. 117 (11), 3530-3539. doi: 10.1172/JCI32420

Ooie, T., Takahashi, N., Saikawa, T., Nawata, T., Arikawa, M., Yamanaka, K., et al. (2001). Single oral dose of geranylgeranylacetone induces heat-shock protein 72 and renders protection against ischemia/reperfusion injury in rat heart. Circulation 104 (15), 1837-1843. doi: 10.1161/hc3901.095771

Pajohanfar, N. S., Mohebbi, E., Rad, A., Pejhan, A., Nazemi, S., and Amin, B. (2017). Protective effects of atorvastatin against morphine-induced tolerance and dependence in mice. Brain Res. 1657, 333-339. doi: 10.1016/ j.brainres.2016.12.028

Perez-Casanova, A., Noel, R. J.Jr., Rivera-Amill, V., Husain, K., and Kumar, A. (2007). Morphine-mediated deterioration of oxidative stress leads to rapid disease progression in SIV/SHIV-infected macaques. AIDS Res. Hum. Retroviruses 23 (8), 1004-1007. doi: 10.1089/aid.2006.0286

Qin, W., Zhang, L., Tang, K., Zhao, L., Mao, M., Wang, Y., et al. (2019). Effect of heat shock protein 70 modulators on the development of morphine analgesic tolerance in rats. Behav. Pharmacol. doi: 10.1097/FBP.0000000000000528

Qu, J., Tao, X. Y., Teng, P., Zhang, Y., Guo, C. L., Hu, L., et al. (2017). Blocking ATP-sensitive potassium channel alleviates morphine tolerance by inhibiting HSP70-TLR4-NLRP3-mediated neuroinflammation. J. Neuroinflammation 14 (1), 228. doi: 10.1186/s12974-017-0997-0

Saify, K., Saadat, I., and Saadat, M. (2016). Down-regulation of antioxidant genes in human SH-SY5Y cells after treatment with morphine. Life Sci. 144, 26-29. doi: 10.1016/j.lfs.2015.11.014

Saitoh, M., Nishitoh, H., Fujii, M., Takeda, K., Tobiume, K., Sawada, Y., et al. (1998). Mammalian thioredoxin is a direct inhibitor of apoptosis signalregulating kinase (ASK) 1. EMBO J. 17 (9), 2596-2606. doi: 10.1093/emboj/ 17.9.2596

Samarghandian, S., Afshari, R., and Farkhondeh, T. (2014). Effect of long-term treatment of morphine on enzymes, oxidative stress indices and antioxidant status in male rat liver. Int. J. Clin. Exp. Med. 7 (5), 1449-1453. doi: 10.1007/3540-64383-4_22

Shen, L., Wang, W., Li, S., Qin, J., and Huang, Y. (2018). NMDA receptor antagonists attenuate intrathecal morphine-induced pruritus through ERK phosphorylation. Mol. Brain 11 (1), 35. doi: 10.1186/s13041-018-0379-2

Skrabalova, J., Drastichova, Z., and Novotny, J. (2013). Morphine as a Potential Oxidative Stress-Causing Agent. Mini Rev. Org. Chem. 10 (4), 367-372. doi: 10.2174/1570193X113106660031

Tanito, M., Kwon, Y. W., Kondo, N., Bai, J., Masutani, H., Nakamura, H., et al. (2005). Cytoprotective effects of geranylgeranylacetone against retinal photooxidative damage. J. Neurosci. 25 (9), 2396-2404. doi: 10.1523/ JNEUROSCI.4866-04.2005

Trivedi, M. S., and Deth, R. (2014). Redox-based epigenetic status in drug addiction: a potential contributor to gene priming and a mechanistic rationale for metabolic intervention. Front. Neurosci. 8, 444. doi: 10.3389/ fnins.2014.00444

Trivedi, M., Shah, J., Hodgson, N., Byun, H. M., and Deth, R. (2014). Morphine induces redox-based changes in global DNA methylation and retrotransposon transcription by inhibition of excitatory amino acid transporter type 3- mediated cysteine uptake. Mol. Pharmacol. 85 (5), 747-757. doi: 10.1124/ mol.114.091728

Wang, Y. T., Qin, W. J., Liu, Q., Li, Y. L., Liang, H., Chen, F., et al. (2014). Chaperone heat shock protein 70 in nucleus accumbens core: a novel biological target of behavioural sensitization to morphine in rats. Int. J. Neuropsychopharmacol. 17 (3), 469-484. doi: 10.1017/S1461145713001429

Wang, B., Su, C. J., Liu, T. T., Zhou, Y., Feng, Y., Huang, Y., et al. (2018). The neuroprotection of low-dose morphine in cellular and animal models of parkinson's disease through ameliorating endoplasmic reticulum (ER) stress and activating autophagy. Front. Mol. Neurosci. 11, 120. doi: 10.3389/ fnmol.2018.00120

Yan, T., Rizak, J. D., Yang, S., Li, H., Huang, B., Ma, Y., et al. (2014). Acute morphine treatments alleviate tremor in 1-methyl-4-phenyl-1,2,3,6tetrahydropyridine-treated monkeys. PloS One 9 (2), e88404. doi: 10.1371/ journal.pone.0088404

Yang, H., Sun, J., Chen, H., Wang, F., Li, Y., Wang, H., et al. (2019). Mesenchymal stem cells from bone marrow attenuated the chronic morphine-induced cAMP accumulation in vitro. Neurosci. Lett. 698, 76-80. doi: 10.1016/ j.neulet.2018.12.046

Zeng, X. S., Jia, J. J., Kwon, Y., Wang, S. D., and Bai, J. (2014). The role of thioredoxin-1 in suppression of endoplasmic reticulum stress in Parkinson disease. Free Radic. Biol. Med. 67, 10-18. doi: 10.1016/j.freeradbiomed.2013.10.013

Zeng, X. S., Jia, J. J., and Ma, L. F. (2015). Gensenoside Rb1 protects rat PC12 cells from oxidative stress-induced endoplasmic reticulum stress: the involvement of thioredoxin-1. Mol. Cell Biochem. 410 (1-2), 239-246. doi: 10.1007/s11010015-2557-1

Zeng, X. S., Geng, W. S., Chen, L., and Jia, J. J. (2018). Thioredoxin as a therapeutic target in cerebral ischemia. Curr. Pharm. Des. 24 (25), 2986-2992. doi: 10.2174/ 1381612824666180820143853

Zhang, Z., and Pan, Z. Z. (2010). Synaptic mechanism for functional synergism between delta- and mu-opioid receptors. J. Neurosci. 30 (13), 4735-4745. doi: 10.1523/JNEUROSCI.5968-09.2010

Zhang, X., Bai, L., Zhang, S., Zhou, X., Li, Y., and Bai, J. (2018). Trx-1 ameliorates learning and memory deficits in MPTP-induced Parkinson's disease model in mice. Free Radic. Biol. Med. 124, 380-387. doi: 10.1016/j.freeradbiomed. 2018.06.029

Zhang, P., Moye, L. S., Southey, B. R., Dripps, I., Sweedler, J. V., Pradhan, A., et al. (2019). Opioid-induced hyperalgesia is associated with dysregulation of circadian rhythm and adaptive immune pathways in the mouse trigeminal ganglia and nucleus accumbens. Mol. Neurobiol. 56 (12), 7929-7949. doi: 10.1007/s12035-019-01650-5

Conflict of Interest: The authors declare that the research was conducted in the absence of any commercial or financial relationships that could be construed as a potential conflict of interest.

Copyright (c) 2020 Zeng, Geng, Wang and Jia. This is an open-access article distributed under the terms of the Creative Commons Attribution License (CC BY). The use, distribution or reproduction in other forums is permitted, provided the original author(s) and the copyright owner(s) are credited and that the original publication in this journal is cited, in accordance with accepted academic practice. No use, distribution or reproduction is permitted which does not comply with these terms. 